Int. J. Dev. Biol. 53: 753-763 (2009)

doi: $10.1387 / \mathrm{ijdb} .072497 \mathrm{kw}$

\title{
The cooperative genome: organisms as social contracts
}

\author{
KENNETH M. WEISS ${ }^{*, 1,2}$ and ANNE V. BUCHANAN ${ }^{1}$ \\ Departments of Anthropology ${ }^{1}$ and Biology ${ }^{2}$, Penn State University, University Park, PA, USA
}

\begin{abstract}
A predominant theme in much of evolutionary biology is that organisms are the product of relentless and precise natural selection among them, and that life is about the competition of all-against-all for success. However, developmental genetics has rapidly been revealing a very different picture of the nature of life. The organizing principles by which organisms are made are thoroughly based on complex hierarchies of molecular interactions that require multiple factors to be relentlessly cooperating with each other. Reconciling these two points of view involves changing the scale of observation, and a different understanding of evolution, in which cooperation and tolerance are more important than competition and intolerance.
\end{abstract}

KEY WORDS: evolution, cooperation, developmental genetics, patterning

"The state of men without civill society... is nothing else but a meere warre of all against all."

Thomas Hobbes, De Cive, 1642.

Imagery can be useful, even in science. But it can also be misleading. The $19^{\text {th }}$ Century British sociologist Herbert Spencer, even before reading Darwin's Origin of Species (Darwin, 1859), proposed that societies change competitively and the best (like Imperial England) succeed at the expense of others because it is Nature's way. After he read the Origin, he suggested the phrase 'survival of the fittest' to evoke the ruthless competition that he saw as being at the root of Nature. Darwin and Wallace had originally used the term 'natural selection' but later adopted Spencer's phrase. In part, this was because the term 'selection' might be interpreted to mean an external or conscious Selector, rather than a totally impersonal natural process. And 'survival of the fittest' fit Darwin's idea that selection detected, as he put it, the 'smallest grain in the balance' of organismal differences (Weiss, 2004).

One might object that of course it isn't only 'the fittest' who survive and reproduce, but the phrase and the notion that what is here today must be here for a selective reason is widespread, and evokes the imagery of pervasively hostile and exclusively competitive Nature. Such imagery has become commonplace in biology_including in developmental biology (Carroll, 2006), and indeed in society more generally, where Hobbes' image of a war of all against all wears the cloak of today's pervasive competitivemarket ethos. However, progress in developmental biology has been steadily, if quietly, revealing facts that challenge this view of life. Life at all levels, from genes to ecosystems, is much more about cooperation than competition. We might even turn the common view on its head and ask whether the function of cooperation in life is to enhance competitive advantage, or the function of competition is to enable cooperation. A more apt image would be one in which life's basic entities are essentially intertwined, and succeed by banding together in the cellular societies we call organisms, where they wend their way through life together.

\section{A matter of observational scale}

Historically, at any given time the theoretical basis of a science predominantly addresses a particular perspective or scale of observation. The contrasts between Ptolemaic and Copernican astronomy, Euclidean and Riemannian (spherical) geometry, or Newtonian and Einsteinian physics are like that. When explanations that sufficed on one scale are found to be inadequate on another, the theory undergoes adjustment.

Ever since Darwin, the center of gravity in biology has been evolution, and the long term perspective that this implies has held sway for a century and a half. Evolutionary theory was developed for the particular problem Darwin and Wallace were trying to solve: to provide a mechanistic account of the origin, diversity, and adaptive nature of species. Because the events took place unimaginably slowly, the heart of the theory was to explain the accumulated product of the deep, unobserved past. Darwin and Wallace viewed life as the result of a determinative Newtonianlike continuous process of natural selection, at a time in the history of science that was about the discovery of universally applicable laws of Nature. The result was a kind of selectionist manifesto, a tidy, simple, unitary law of all-seeing Nature that applied continu-

\footnotetext{
Published online: 1 June 2009.

*Address correspondence to: Dr. Kenneth M Weiss. Department of Anthropology, Penn State University, University Park, PA 16802, USA.

Fax: +1-814-863-1474. e-mail: KenWeiss@psu.edu - web: http://www.anthro.psu.edu/weiss_lab 
ously and infinitesimally, the same way that gravity-the imagery with which Darwin concluded the Origin-was assumed to work. This view still captures the imagination, and it is common if not routine for each trait, factor, or gene to be explained in terms of what it was 'selected for.' This was the classical evolutionary theory and is still widely treated as the default if implicit view of most biologists today, with even the existence of genetic drift treated as a functionless statistical noise around the molding signal of selective force.

There are at least two problems with this view. When selection at any given time is weak, or very weak (or, as may be typical, very veryweak), the Brownian motion of genetic drift can be comparably important in determining the ultimate fate of genetic variation (Ohta, 1992; Ohta, 2002; Weiss, 2004). Typical average selection coefficients on the order of $10^{-4}$ or so, turn the idea that a given allele or genotype has a single, persistent (much less inherent) selective value into almost a philosophical if not illusory metaphysical concept. This is because it can be statistically or even epistemically impossible to obtain enough data to demonstrate this 'force,' or to determine whya given genotype left more copies than some other one did.

And this raises the second problem, which is one of time compression. Adaptation is the cumulative result of whatever factors brought it about, and when comparing modern species functionally to each other, or to ancestral fossils, it is easy to hold an image of biological change as orderly, steady, and directed by selection for some persistent functional reason. It is easy to imagine that we can see the signal, much more difficult to see the noise. Darwin knew very well that his argument rested on the assumption called uniformitarianism, essentially that the forces we can actually see at work today can be extrapolated into the deep past. Implicitly invoking this idea, the selective cause is often equated to present function.

A view of natural selection as a force with zero tolerance risks not just being vacuously tautological, since what is here today had to be adaptive or it wouldn't be here at all, but the search for selective explanation has distracted attention from other aspects of life. For example, from Darwin's time to the late $20^{\text {th }}$ century, most prominent biologists considered embryology to be mainly a source of knowledge that illuminated our understanding of evolution, rather than as important on its own theoretical merit (Gilbert et al., 1996; Mayr, 1982; Laublichler and Maienschein, 2007; Mayr and Provine, 1980). In Dobzhansky's iconic phrase, that has been repeated countless times, "Nothing in biology makes sense except in the light of evolution." (Dobzhansky, 1973; Dobzhansky, 1964)

However, life occurs on the short term developmental time scale rather than the deep evolutionary one, and is about what happens from cell to cell and day to day. To lay the groundwork for understanding the implications of these differences, some broad characteristics of life on these time scales are provided in Table 1 (e.g., for discussion see Weiss, 2005; Weiss and Buchanan, 2004; Weiss and Buchanan, 2009). Perhaps the most important difference is that evolution is about how interactions among organisms with different genomes diverge competitively over generations of organisms to produce many species, while development concerns interactions among cells with the samegenome that differentiate cooperatively over generations of cells to produce a single organism.
These facts are known in principle, of course, but their difference is rather more remarkable than usually seems to be realized. Much of biology is devoted to explaining the differences between species, such as between a chimpanzee and a human, mouse and rat, or oak and a maple, that are due to genomes having accumulated differences over thousands or millions of generations. Yet these differences are almost trivially small compared to the differences between a brain and a braincase, or a finger and an eye, which must be produced by cells with the same genome, sometimes quickly within a few cell generations rather than over thousands of years, and in the same individual.

For most of the last century, the theoretical principles of evolution seemed sufficient to account for transformative change over time while largely treating the phenogenetic mechanisms, that is, the means by which genotypes produce phenotypes, as black-boxes. The evolving traits themselves were seen as so complex that they were simply said to evolve by changes in gene frequencies, tacitly referring that to changes in protein structure. But theoretical notions like survival of the fittest don't take us very far in explaining the real organisms that are doing the evolving.

However, thanks to dramatic technological advances, a triumph of recent developmental biology has been that phenogenetic processes are leaving their black-box status, and becoming understandable in terms that are just as theoretically tractable and rigorous as evolutionary theory. Surprisingly, as papers in this special issue of the IJDB reflect, while this new knowledge doesn't make complex traits simple, it does show how complex traits can be made simply. And when we focus on life on its more immediate time scale, and understand the processes by which complexity comes about, we see the inadequacy of survival of the fittest even on the evolutionary time scale.

\section{Complexity made simply: the phenogenetic logic of life}

Phenogenetic principles can be characterized in various ways, and different authors place stress on different aspects (Amundson, 2005; Carroll et al., 2004; Davidson, 2001; Davidson, 2006; Gerhart and Kirschner, 1997; Gilbert, 2003; Hall, 1999; Raff, 1996; Weiss, 2005; Weiss and Buchanan, 2004; Wilkins, 2002). Table 2 presents one way to describe these ideas, which can be characterized as the basic principles of phenogenetic logic. 'Logic' is an appropriate concept, because phenogenetic phenomena are the higher-order emergent results of interactions: life is organized by relational principles-the presence, absence, combinations, and arrangements of effectors of various kinds.

These principles have been individually noted before, in one form or another, some of them quite long ago. Investigators have usually invoked them singly, in some particular context, and until recent years there has been insufficient knowledge to relate the principles, as a set, to their genetic basis. Genes underlying complex traits were necessarily invoked in absentia. Importantly, one could not know the extent to which widely diverse and developmentally unrelated instances shared a similar genetic logic even when the specific genes were entirely different, as for example, in plants and animals. But that kind of generalization is now possible, and a synthesis that applies to life across its diversity of form and time is emerging.

The principles in Table 2 comprise a kind of pull-down menu that expands on the general over-arching notion of duplication 
with variation given in Table 1. The principles are simple, straightforward, and of course highly inter-related. The following discussion concerns their application to patterning phenomena on the developmental time scale. But life is a single phenomenon, and the principles also apply in various ways on the evolutionary time scale, as well as on the ecological scale of interactions among organisms. In fact, they form a superset with classical evolutionary principles, but include important aspects of life on which, as we have noted above, evolutionary theory is essentially silent. However, the following brief discussion is aimed at sketching out the way in which these basic phenogenetic principles suggest a need to temper the standard evolutionary view.

Inheritance with memory on both time scales refers to transmission from cell to cell of information relative to the cell state. The genome is the primary and most durable source of inherited memory, although other forms of inheritance are important as well in the shorter term. On the evolutionary time scale, mutation across germlines is the archetype of change. These changes can persist for countless generations, and are the essential feature of organismal differentiation on the evolutionary scale. Sequence mutation also occurs in somatic cells, and can last for the cellular generations within individual organisms' lives. It creates some individual-specific tissue mosaicism and is vital to some systems such as vertebrate olfaction and adaptive immunity.

However, the predominant type of genetic change on the developmental time scale is different. The parts of an organism must work as a unit, yet except for somatic mutation, all of its cells have essentially the same genome. As has been clearly revealed by countless experiments in recent decades, the essential feature of cellular differentiation on the developmental scale is change in gene expression among cells carrying that common genome sequence. Despite some specialized exceptions, this change is effected not by sequence mutation but by a variety of other mechanisms. One major factor is the context-specific presence of

TABLE 1

\section{EVOLUTION AND DEVELOPMENT COMPARED}

\begin{tabular}{lll} 
& Evolution & Development \\
\hline Overall & Descent with modification & Duplication with variation \\
Due to & Change in gene sequence & Change in gene expression \\
Enabled by & Reproductive isolation & Modular sequestration of cells of organisms \\
Changed by & Competitive adaptation & Cooperative differentiation \\
Variation & Change by undirected chance & Change by directed induction \\
Interactions & Among different genotypes & Among copies of same genotype \\
Genome effect & Permanent, sequence change & Temporary, sequence modification \\
Time scale & Generations of organisms & Generations of cells \\
\hline
\end{tabular}

TABLE 2

SOME GENERAL PRINCIPLES OF LIFE

\begin{tabular}{lll}
\hline 1 & Inheritance with memory \\
2 & Modular organization \\
3 & Sequestration, but partial \\
4 & Combinatorial coding \\
5 & Contingency and chance \\
6 & Adaptability in the face of change \\
7 & Cooperation of multiple pieces fitting together \\
\hline
\end{tabular}

modifying factors, like transcription factor proteins, that cause differential transcription of regions of DNA. In addition, 'epigenetic' changes modify DNA without changing its nucleotide sequence, such as by acetylation of histones affecting chromatin packaging, and local nucleotide methylation. These modifications affect the accessibility of local DNA to transcription machinery, but don't change its nucleotide sequence. The expression state of a new cell is inherited from its parent cell. Somatic gene expression states are permanent in descendent cell lines within the lifetime of an organism, in the same sense that sequence mutations are permanent across germ lines in evolutionary time: both are faithfully inherited until altered by circumstances.

Cellular life implies modular life, but modular organization is ubiquitous from the subcellular to the ecological. The nature of information storage in genomes is modular, including exons, centromeres, enhancers, insulators, repressors, promoters, telomeres, dispersed repeat elements, and many other structures, as well as a host of recently discovered and poorly understood kinds of modular sequence elements including a much higher proportion of DNA transcribed into RNA than had been thought (e.g., Birney et al., 2007; Kapranov et al., 2007a; Kapranov et al., 2007b; Willingham etal., 2006). If they are anything, genomes are the billion-year product of duplication events that generate functional modules.

But DNA is only the beginning of modularity. From intracellular to multicellular organization, organisms are divided into sections-tissues, organs, organ systems. These are often produced by further modularization, as intestinal villi, leaves, hair, and skeletal elements exemplify. Modules can be themselves subdifferentiated, and the pattern of modularity can be symmetrical or asymmetrical, can change along anatomic axes (as, for example, vertebrae or vertebrate intestinal structures, or the nature of fly segments from mouth to tail). Modularity can be virtual as well, as apparently is the case with mammalian brain functions that involve and integrate different morphological modules in the brain. Physiological systems also have modularly organized function, as for example vertebrate reproductive hormones or lipid transport.

Modular organization is brought about in many ways, including branching, the establishment of symmetric and asymmetric axes, and repetitive patterning of many different kinds, such as by serial homology. These processes are ubiquitous in plant and animal life, and have been given extensive treatment in recent works (e.g., Amundson, 2005; Carroll et al., 2004; Chuong et al., 2005; Davidson, 2001; Gerhart and Kirschner, 1997; Gilbert, 2003; Hall, 1999; Kirschner and Gerhart, 2005; Lynch, 2007b; Murray, 2002; Nijhout, 1991; Ohno, 1970; Raff, 1996; Wagner and Schlosser, 2003; Webster and Goodwin, 1996; Weiss and Buchanan, 2004; Wilkins, 2002; Wolpert, 1996; Wolpert et al., 1998; Wray, 2003; Wray et al., 2003).

In these processes, otherwise apparently uniform sheets of cells are induced to transform into various kinds of topobiology (Chuong etal., 2005), through genetic mechanisms that are being rapidly discovered, and many of which are discussed in this issue (although at the level of gene expression, sheets of cells may not be as completely uniform as they physically appear, but may include regional differences, as for example, in the ability to respond to external conditions). The general underlying idea of some of these processes was anticipated speculatively long 
before there was any kind of genetic confirmation (e.g.,Bateson, 1894; Gilbert, 2003; Turing, 1952; Waddington, 1942; Waddington, 1962; Wolpert, 1996). One illustrative case is the history of ideas about repetitive patterning by internally or self-actuating quantitative reaction-diffusion-like mechanisms, that have been mimicked very closely by computer simulation (Jernvall and Thesleff, 2000; Meinhardt, 1996; Meinhardt, 2001; Meinhardt, 2003; SalazarCiudad, 2006a; Salazar-Ciudad, 2006b; Salazar-Ciudad and Jernvall, 2004; Salazar-Ciudad and Jernvall, 2005; SalazarCiudad et al., 2003 and see related paper in this issue) which was then shown experimentally to work basically as hypothesized (Maini et al., 2006; Pispa et al., 1999; Sick et al., 2006). An important aspect of these discoveries that makes the principles general is that the logicis shared among diverse traits in unrelated embryologic lineages (fate-map clades) within and between plants and animals, and involve totally unrelated genes (e.g., see Weiss and Buchanan, 2004).

Modules are in a sense by definition isolated, or sequestered, from each other. Sequestration is a kind of sine qua non for differentiation, and the evolution of life into membrane-enclosed compartments (cells) can be viewed as having succeeded because of this feature. Cells have their own internal membraneenclosed sequestered units such as nuclei and various organelles, and there are also chemically-based local sequestered environments as well and even sequestering molecules (e.g., heat-shock proteins). Darwin was plagued by the knowledge that his blending theory of inheritance would not support his ideas about the evolution of species (Darwin, 1900), but in fact even his 'gemmules', and similar ideas about inheritance that go back at least to Hippocrates, involved different, sequestered elements that were responsible for an organism's different cells and tissues.

Sequestration allows each module to do its own thing and go its own way. When sequestered modules develop hierarchically, inheritance with memory of gene expression states allows their trees of descent to become increasingly divergent in gene expression, and hence in morphology or behavior. The same is in fact true from developmental fate maps to adaptive speciation on the evolutionary scale.

Sequestration allows organs to develop independently, but sequestration usually is only partial, especially on the developmental scale. Individual modules within or even between body systems usually have some communication with each other, which is why organisms are distinct entities. The fact that speciation only occurs when sequestration in the form of reproductive isolation is so complete that divergence can increase without limit has been central to evolutionary theory since the Modern Synthesis in the early $20^{\text {th }}$ century, and is only gradually losing its status as an evolutionary dogma, as some mechanisms of sympatric isolation are identified.

Though it is never characterized in this way, developmental differences among cell types within an organism are similar in important ways to speciation among organisms. Cells, such as root and leaf, or stomach and muscle, are isolated from each other, irrevocably incompatible, although they may communicate by signalling, just as pheromones signal between individuals or flowers to bees. Yet, on the developmental time scale this 'cytospeciation' occurs among cells with genomes that are essentially the same (differing only by a modicum of random somatic mutation).
It is one thing to describe life as based on partial sequestration, and another to provide a mechanism of communication to account for its partial nature. This, too, has been one of the principle discoveries of the last generation of developmental genetics. Developmental communication involves simple and rather ubiquitous combinatorial logic, one of whose pervasive manifestations is signalling. Combinations of expressed gene products, and their arrangement in space and time, determine the state of a cell on the developmental scale of life. Cells are induced by signals to alter gene expression patterns. Signalling commonly involves cascades begun by signal factors being received by cell-surface proteins and signals can come from the same cell, distant cells in the organism, or chemicals or even other species in the external environment.

Signalling usually involves the simultaneous presence of many different factors. The sets of factors constitute combinatorial codes. These really are codes; that is, the physical traits of the coding elements are unrelated to the physical result; it is their combination that carries the requisite information. That these are properly arbitrary codes is shown by the typical finding that the same coding elements are often pleiotropic, used in many different contexts and sometimes at the same time in different parts of the same embryo, or in the same structure at different times. Indeed, the codes themselves are only partially sequestered from each other, in that there may be cross-reaction among members of the gene families that are involved (e.g., between different FGF receptors responding to a given FGF signal factor). It is perhaps an irony of ironies that similar signalling processes are responsible for establishing sequestered units and then establishing the communication that keeps their isolation from being complete.

The communication that prevents complete sequestration of the components of a dynamic system, among molecules within a cell, cells within an organism, organisms within a species, or species within an ecosystem, is based on arbitrary combinatorial coding. The use and reuse of coding elements enables flexibility in development and its evolution. But these same facts mean that the combinations and locations cannot be independent, but must instead be highly coordinated in space and time: there is no aboriginal egg followed by a subsequent chicken.

Combinations of multiple hierarchical as well as co-occurring cascades, rather than just one, are typically responsible for the dance of differentiation that is morphogenesis. To paraphrase Louis Pasteur's oft-cited statement that 'chance favors the prepared mind', we might say that differentiation favors the prepared cell. A cell must express the appropriate set of receptors, second messengers, and transcription factors, their modifiers and enablers, and many other ancillary genetic components needed to respond to a particular combination of signals. In turn, this means that the cooperative nature of development requires that some prior signalling enables the enablers. It is in this sense that we suggested above that even what appear to be uniform sheets of predifferentiated cells may not be entirely uniform: they may differ in some spatially systematic way in the signals to which they can respond.

Maps of signal cascades, like WNT or FGF signalling, involve spaghetti-like pathways that may seem horribly complex. However, this may partly be the result of the way that networks are identified experimentally, which could make them seem more complex than they are, and not all of the pathways may be used 
in each cellular context. This could be interpreted as suggesting that cellular life is not so complicated after all. But, a path taken implies paths not taken. Signalling only works if the genes to be activated are 'open for business' by appropriate stripping of nearby histones and other epigenetic garnishes, and the regulatory sequences flanking the appropriate genes have to be present in the individual's DNA: they can't have mutated away. Repression, by omission or commission, of the pathways not to be taken is but another form of combinatorial coding, with 'off' as actively regulated as 'on'.

All of these phenomena are contingent, in that the stage must be properly set in the proper order for the drama of sequestered, hierarchical cell-fate lineages to be established in embryogenesis. The more genes and regulatory sequences involved, the greater the target they present for mutations, hence variation. This explains the healthy amount of adaptability that is observed, as organisms from embryo to adult assess their circumstances and respond accordingly. Adaptability of various, and often subtle kinds is a ubiquitous feature of life in all its scale perspectives (Gilbert, 2001; Gilbert, 2005; Gilbert and Bolker, 2003; Hall, 1999; Jablonka and Lamb, 2006; Oyama, 2000; Oyama et al., 2001; Schlichting and Pigliucci, 1998; Weiss and Buchanan, 2004; West-Eberhard, 2003; Wilkins, 2002). In addition, chance events of all sorts are ubiquitous, so that throughout life organisms must be able to accommodate these, as well as the more programstaged developmental contingencies.

Together, the plethora of factors that must be expressed in the right place and time for the principles we have discussed to work shows that life is largely about cooperation. An organism is the result of countless specific molecular interactions including DNA and RNA interaction and self-interaction, protein-DNA, proteinRNA, and protein-protein binding, working together, at the right times and places. This is true at the organ-system, organ, tissue, cell, and gene levels.

Organisms can succeed, and hence evolve, only as these complex cooperative interactions also succeed at any given time. The intricately cooperative nature of development at the molecular interaction level raises the question of how this happens on the evolutionary time scale since an interaction is a partnership between at least two factors that cannot change independently if the partnership is still to work: a changed key may no longer open the lock. The principles of development that we have sketched out, based on the burgeoning knowledge from research in developmental genetics, show the inadequate nature of evolution viewed simply as relentless competition, and treated as if each gene independently faces the relentlessly competitive rigors of Survival of the Fittest.

\section{The evolution of cooperation, or coevolution}

From a classically selection-driven perspective, cooperation is viewed as but a form of competition in disguise: if cooperation involves a cost, it can only come about if it succeeds in competitively limiting environments: cooperating entities succeed only because they out-compete less cooperative entities. An increase in the frequency of genetic variants can unfalsifiably be attributed to competitive advantage. This is not the place to debate such strong selectionistic assertions, because regardless of their evolutionary accuracy, a competition-based perspective may not be the best one for understanding the genetics of development on its own level of organization in the biological time scale of the hereand-now, where cooperation is manifestly pervasive.

We are by no means the first to question the ubiquity of finetuning by natural selection as the essence of life. Challenges, which have been raised ever since Darwin's own time, have come from several quarters. Not all of them have been equally credible, but many of them are. To mention just a few recent examples, mutation and genetic drift, along with gene duplication, are demonstrably more important than usually considered, and can be more important than selection (Lynch, 2007a; Lynch, 2007b; Nei, 2005; Weiss, 2004; Weiss and Buchanan, 2004, 2009), and once complex mechanisms have evolved, the possibility that they might be remodelled by selection diminishes at least somewhat (Kirschner and Gerhart, 2005; Weinreich et al., 2006). Other authors search for ways in to explain what we are calling 'cooperation' within a Darwinian paradigm, including aspects of slippage between genotypes and phenotypes or quasi-independent modularity, or discuss how what we know about development differs from the classically simple logic of inheritance and Darwinian selection in multicellular evolution (Hall, 1999; Herre et al., 1999; Laublichler and Maienschein, 2007; Leigh and Rowell, 1995; Newman, 2005; Nowak, 2006; Wilkins, 2002).

It is certainly fair to ask how such a sea of cooperation could possibly evolve. If evolution is such an intense race of each 'selfish gene' for itself, the pervasively cooperative nature of life would force us to meditate on something akin to the Zen concept of one hand clapping. Instead, we need to understand how two clapping hands can evolve together.

Indeed, if recent discoveries have shown us anything, it is that development and gene usage are more like a whole audience clapping, with ever more, never fewer, subtle mechanisms and factors. The contributing factors that must remain compatible with each other include a plethora of recently discovered, partially understood, noncoding RNAs that appear to be involved in many pre- and post-transcriptional phenomena that titrate the level or timing of gene expression (Birney et al., 2007; Kapranov et al., 2007a; Kapranov et al., 2007b).

The cooperating elements include the many transcription factors that must bind to regulatory sequences, and to each other, to cause a gene to be expressed in a given cell (and the relevant flanking DNA has had to be exposed for these proteins to reach it). An example is given in Fig. 1. Each transcription factor protein must be expressed in the cell, and its target genes must have one or more flanking regulatory sequences that are recognized by those binding domains. Every signal factor and its receptor(s) must possess the right structures for ligand-receptor binding to occur. The elements must bind to their DNA and often to each other, but the details vary considerably among co-expressed and orthologous genes in related species (e.g., Brown et al., 2007; Ludwig et al., 1998; Nonchev et al., 1996).

These factors need to be compatible not just with each other, but internally with themselves. Signaling and transcription related proteins must fold into their appropriate functional shape, which means appropriate interaction among appropriate amino acids properly spaced, which requires highly structured coding sequence. Likewise, to fold into proper shapes, functional RNAs such as tRNA, rRNA, and others must have complementary nucleotides in the right positions. This is shown by examples in 


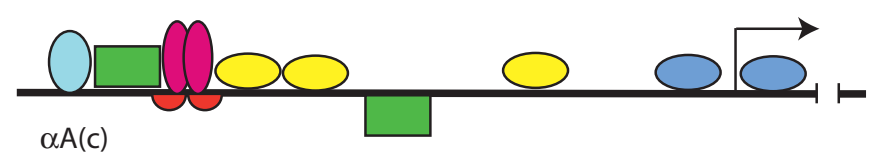

$\alpha A(m)$

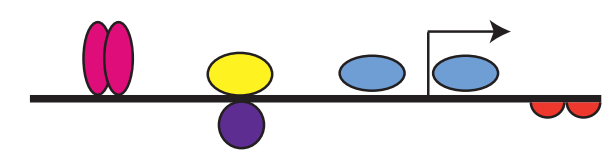

$\delta 1(c)$

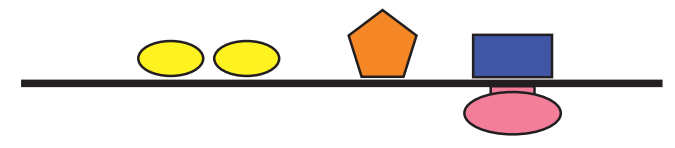

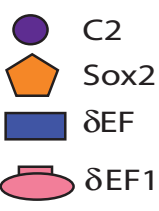

Fig. 1. Cooperation through tolerance of piecemeal change. ProteinDNA and protein-protein interactions of transcription factors involved in the expression of two chicken $(c)$ and one mouse $(m)$ lens crystallin genes. The factors vary in the presence, combinations, interactions, and locations, and include Pax-6, a gene with important phylogenetically conserved function in the development of photoreception. Redrawn and simplified for schematic illustrative purposes from Cvekl and Piatigorsky (1996) and Davidson (2001).

Fig. 2 and Table 3. In order to move from one functional state to another, many changes may be required, implying that the system tolerates the piece-meal accumulation of changes, since multiple fortuitous mutations won't occur simultaneously with more than trivial probability (Ancel and Fontana, 2000; Fontana, 2002; Fontana and Schuster, 1998; Kashtan et al., 2007 to cite a few examples).

Success for an embryo can be equated to its remaining within acceptable perimeters of this high-dimensionality genetic statespace. If so large a number of genetic factors are required to work together to produce a developmental or morphogenic trait, they cannot simply compete as independent warring entities because their evolutionary success is a complex collaborative matter. Independent evolution of each component, and their own internal components, could require too great a genetic load for organisms like vertebrates to be able to generate enough excess reproduction to sustain the amount of selective loss that pruning such large DNA targets of mutations would present. So how can we account for observed developmental genetic architecture in a way that is compatible, as it must be, with its cooperative evolution, without invoking any mystical mutational foresight?

In fact, we know the answer at least in generic terms. A major part of that answer is tolerance. When the interacting factors responsible for development through the principles outlined in Table 2 are studied by experimental manipulation or by observa- tion of existing variation, tolerance is routinely observed. As one illustration, there is considerable variation in the DNA regulatory binding sequences recognized by transcription factor proteins, as exemplified in Table 3 (Balhoff and Wray, 2005; Matys et al., 2003; Matys et al., 2006; Wray et al., 2003). Likewise, protein interactions, anti-codon/codon pairing, and auto-annealing of RNA shown in Figures 1 and 2 also tolerate at least some mismatching (Ancel and Fontana, 2000; Fontana, 2002; Fontana and Schuster, 1998; Kashtan et al., 2007 to cite a few examples). Indeed, even to use the term 'mismatching' reflects a subjective Darwinian bias that there is a right kind of 'match'.

One way to help understand how cooperation not only survives but evolves, is to examine the genetic architecture of complex developmental traits. This is done through several approaches that take advantage of modern statistical and molecular technologies. We can, for example, use naturally occurring or engineered mutations to serve as genetic semaphores for serious dysgenic effects. These indicator genes point us to developmental times or tissues in which the gene is expressed and apparently important, but allow us to identify other cells that the gene's usages affect. Expression profiling and single-gene modification or knockout experiments make it possible to relate the semaphore gene to other genes with which it is co-expressed or whose expression it affects. Of the thousands of genes expressed in the choreography of development, these approaches allow subsets to be identified that appear to operate as 'signaling' systems or networks.

The term may be rather revealing about the competitively hierarchical way current industrial culture tends to conceptualize the world, applied to life. Like a subway system with some main stations, and many small stations along the lines, an integrated signaling system of genetic pathways includes some major or hub genes whose coded proteins interact with those of many other genes, and many spokes, or genes that act at the end of the cascade or have only very local and specific (and minor) effects (e.g., Barabasi and Oltvai, 2004). The most detailed gene-network studies have been in malleable experimental single-celled organisms like yeast (e.g., Boone et al., 2007) that aren't banded together for success the way metazoans are, in which the evidence seems to suggest that a higher fraction of genes have detectably negative effects when deleted (e.g., Eyre-Walker and Keightley, 2007).

We tend to name systems after their semaphore genes, which may take on a de facto role as at least conceptual hubs, as for example WNT-signalling, or PAX-6 as a 'master' gene for eye development. However, even with these genes a common if not typical experience is to find different or no effects among the strains, or even among the individual animals, in which a given transgenic under- or over-expression experiment is done. There are also numerous examples of alleles with very serious consequences in one species that are the normal 'wild type' alleles in closely related species (Gibbs et al., 2007; Kondrashov et al., 2002; Kulathinal et al., 2004), further suggesting fluid, context dependence and tolerance. This is presumably because what seems inherently harmful in one context is not so when there are compensating mutations elsewhere in the gene or genome, so the variation works as a set in its appropriate context. There is also accumulating evidence that the nominal networks, which are often assembled piecemeal in single-factor experiments, may be more complex than the individual cellular reality in which, in a 
given developmental context, organisms can survive the modification or even loss of genes in a network or use only a part of it, Changes in regulation and hence major as well as minor function seem to be built to an important extent by the gradual accumulation of new regulatory regimes, enabled by the highly polymorphic and hence variation-tolerant nature of existing regulatory (Hinman and Davidson, 2008; McGregor etal., 2007; Oliveri and Davidson, 2007; Stern, 2007; Wray, 2003; Wray et al., 2003) Because of the short nature of protein-DNA binding sequences in regulatory elements, they can be built up rather easily by random mutation. And, organisms can switch networks, depending on circumstances, and still maintain homeostasis.

But this is experimental manipulation, and usually done on inbred lines of model organisms. It reveals nominal genetic mechanisms, but is less informative about their tolerance for natural variation. One approach to understanding the latter is to evaluate the selective effects of mutations (on organisms, not cells within them, which is a more problematic matter to investigate) with genomewide mapping. For complex traits this includes QTL (Quantitative Trait Locus) mapping, which involves searching normally existing variation, by studying its occurrence in families, pedigrees, or genealogies of humans or model organisms. The search identifies genome regions and their genes, in which the genetic variation is associated with phenotypic variation in the related plants or animals. The work and genotyping expense of such studies is justified by heritability estimates, that typically show that a substantial fraction, usually around $40-60 \%$, of the observed variation is inherited, based on correlations between phenotype and kinship relationships among the sampled individuals.

QTL mapping commonly identifies a small number of chromosomal regions (called QTLs) that show at least statistically suggestive significant effects on the phenotypic variation. The effects of individual QTLs are usually modest, and account for only a fraction of the overall heritability. The latter appears to be due to polygenic effects, that is, to the aggregate of a large number of loci with individually undetectable effects. Implicit in but central to a polygenic model, whose formal specification goes back at least to Fisher in 1918 (Fisher, 1918), is that there is phenogenetic equivalence, that is, many different genotypes can produce essentially the same phenotype. When many loci have individually small effect, even when the organisms are subject to substantial selective forces, adaptive fitness will be distributed across the contributing loci, and the net fitness effect for any one allele or locus will be very small. As mentioned earlier, the evidence suggests this is the case (Eyre-Walker and Keightley, 2007; EyreWalker et al., 2006; Ohta, 1992; Ohta, 2000; Ohta, 2002), which means that to a considerable extent genetic drift has an effect comparable to or even stronger than selection on allele frequency changes within species, or their substitution patterns between species. And with genetic drift can come phenotypic drift.

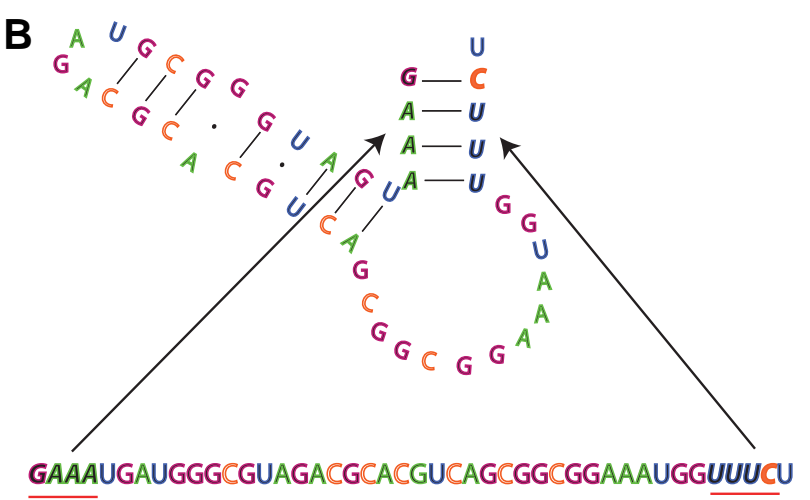

GAAAUGAUGGGCGUAGACGCACGUCAGCGGCGGAAAUGGUUUCU

Fig. 2. Cooperation through base-pairing. Functional RNAs require compatible base-pairs at specific locations in their respective genes. Shapes can usually be retained in the presence of at least some mismatches. (A) A schematic tRNA molecule showing the extensive base-pairing (ladder rungs) required to achieve its functional cloverleaf shape. (B) The human accelerated region 1 (HAR1) functional RNA gene sequence and its apparent conformation, from (Pollard et al., 2006).

Less-than-devastating effects are very difficult to demonstrate naturally because they require considerable sample sizes, precise trait definitions, and the like. The existing evidence is largely statistical in nature, aggregating data across genomes or from different studies. But that evidence suggests that most nondevastating new alleles have little if any marginal phenotypic effect (Eyre-Walker and Keightley, 2007; Eyre-Walker et al., 2006; Ohta, 2002). But alleles or two at one or a few loci, in a given sample or population, have more than trivial phenotypic effects, which are detected as QTLs in mapping studies. The results are often sample-specific, in that the same QTLs are difficult to replicate in other studies, which shows that substantial variation

TABLE 3

\section{SEQUENCE TOLERANCE IN TRANSCRIPTION FACTOR BINDING SITES}

\begin{tabular}{|c|c|c|c|c|c|}
\hline Pos & A & C & G & $T$ & Consensus \\
\hline 01 & 15 & 7 & 6 & 10 & Any \\
\hline 02 & 21 & 9 & 3 & 10 & Any \\
\hline 03 & 10 & 9 & 10 & 18 & Any \\
\hline 04 & 8 & 14 & 9 & 16 & Any \\
\hline 05 & 3 & 2 & 4 & 38 & $\mathbf{T}$ \\
\hline 06 & 2 & 0 & 1 & 44 & $\mathbf{T}$ \\
\hline 07 & 3 & 29 & 1 & 14 & C \\
\hline 08 & 40 & 5 & 1 & 1 & A \\
\hline 09 & 3 & 39 & 0 & 5 & C \\
\hline 10 & 1 & 0 & 44 & 2 & G \\
\hline 11 & 1 & 36 & 7 & 2 & C \\
\hline 12 & 23 & 2 & 1 & 21 & $\mathrm{~A} / \mathrm{T}$ \\
\hline 13 & 1 & 4 & 0 & 42 & $\mathbf{T}$ \\
\hline 14 & 2 & 13 & 26 & 3 & G \\
\hline 15 & 40 & 1 & 6 & 0 & A \\
\hline 16 & 14 & 11 & 15 & 7 & Any \\
\hline 17 & 2 & 4 & 3 & 37 & $\mathbf{T}$ \\
\hline 18 & 1 & 0 & 20 & 25 & $\mathrm{G} / \mathrm{T}$ \\
\hline 19 & 13 & 17 & 9 & 4 & Any \\
\hline 20 & 14 & 8 & 4 & 6 & Any \\
\hline 21 & 4 & 12 & 3 & 9 & Any \\
\hline
\end{tabular}

The position weight matrix, showing the experimentally confirmed relative frequency with which each nucleotide appears in each of the 21 base-pair Pax-6 paired domain DNA binding sites. Source: TransFac data base: www.gene-regulation.com/pub/databases.html\#transfac 
exists at any given time, and that allelic effects are context-specific. Relating this to developmental signalling and control network concepts, some but by no means the majority of identified QTLs are the purported 'major' or hub genes as they have been characterized through the history of discovery, gene expression, or experiment.

It may be that the importance of these hub genes has been overestimated or alternatively, that they really are under strong selective constraint. Consistent with this is the general finding that networks, and perhaps especially their hub genes, are usually pleiotropic or strongly epistatic, expressed in the development of many different, often unrelated traits. Another irony could be that because of their importance, such genes are less likely to be responsible for adaptive change, which instead must be distributed over a polygenic mix of less critical or interconnected pathways. In addition, there is very strong evidence, including the conservation of protein sequences of major developmental genes, that much of adaptive evolution in complex traits involves the fluid nature of short regulatory elements, their number, location relative to a regulated gene, and evolution, and this has implications for ideas about homology as well (Schlosser and Wagner, 2007; Wagner, 2007; Wagner and Pyle, 2007; Wagner and Schlosser, 2003; Wray, 2003; Wray and Abouheif, 1998; Wray et al., 2003).

When genetic architecture is largely polygenic in these ways, cooperative evolution is enabled by the slippage made possible by phenogenetic equivalence, providing many alternative and comparably fit ways to produce an acceptable phenotype. Since fitness is distributed over many loci, each is only weakly constrained by selection at any given time, and there are many equivalently fit means to an adaptive change over longer time periods. Most mutations, if they have an effect at all, will only slightly alter a function, so a mutation that makes one pathway less functional can coast until some secondary change(s) may add new function.

These models and findings are consistent with Darwin's original view of evolution as a process that generally works very slowly and gradually. But this has an implication that is far from the gestalt sometimes associated with a rather autonomic invocation of selection among many biologists. At the gene level gradual adaptation is less specific, less selectively fine-tuned, and more fluid and affected by genetic drift more than in classical models, and quite different from Survival of the Fittest. Indeed, omniscient prescriptive selection may be incompatible with life as it is-far less stereotypical, and dependent at its core upon multiplicities of cooperating, interacting and often exchangeable factors whose fluidity must be tolerated (if not perhaps somehow ultimately though not teleologically favoured) by selection.

If instead of intense scrutiny life is characterized by tolerance for phenogenetic variation because of weak, variable, or permissive selection, high mutation rate (and/or large mutation targets), variable environments, frequency-dependent selection, and 'evolvability' (Queitsch et al., 2002; Sangster et al., 2004), then many possible multiply cooperative interactions can slip under the selective tent. Tolerance rather than specificity probably should be viewed as the default, or ground-state of evolution, as modern developmental biology may be showing at the molecular level.

\section{Conclusion: what is the question?}

Multiple contributing loci and weak selection provide a consis- tent basis for morphogenic evolution, but there is an important consequence of this view. What do we mean when we ask what is the genetic basis of morphogenic patterning? If our goal is to identify pathways involved in some particular model system, like development of the eye or mandible in C57/BI6 mice, then we are well on our way. Comparative experimental results also show that the general network genes and their uses are deeply phylogenetically conserved, with similar effects on the corresponding traits of other species, often shared (if usually modified) as widely as among all chordates, or even vertebrates and invertebrates, with similar findings in plants (e.g., Oliveri and Davidson, 2007). When showing students a fossil baboon or rodent, we can confidently assert that the skull involved BMP and FGF signalling. But that is so generic an answer as to be not much different from the explanations we would have given decades ago: this or that shape is homologous in related animals and must therefore involve homologous genes 'for' the shape.

Yet if what we want to know is what specific genes were responsible for variants in some structure like, say, a shorter jaw in different species of primates, or between fossil ancestors and today's descendants, or even among different individualspresent today, we may be stepping into an epistemic no man's land of unanswerable, and almost meaningless questions. It is generally impossible to assert which genetic variants are responsible for two people having jaws of similar length today, and there is no reason to assume that the same was not true in the past.

In this paper, we have outlined a series of general principles of life and seen their implications for the cooperative nature of the genetic architecture of complex developmental traits. In a time in history that often seems obsessed with competitive fundamentalism, it may have been forgotten that the point of Hobbes' warfare imagery was that society exists to prevent such destructive conflict. The genetic evidence is compatible with a view of evolution as tolerant rather than prescriptive, and the amount of standing variation shows that the same is generally true of the phenotypes that embed the underlying genotypes. This rather changes the important evolutionary question one might ask, from a focus on specific genes to the perhaps more amorphous nature of process.

As we noted earlier, changes of view in science often involve changes in scale. For 150 years, evolutionary theory has had gravitational pull in biology. Because it is concerned with longterm adaptive changes in genes, which are generally treated as black-box causal agents, and because over time some things will become more common, the Darwinian explanation can always be applied in retrospect. Even the evolution of metazoan complexity has typically been explained in classical terms (Buss, 1987; Hall, 1999; Wilkins, 2002) or by attempts to reconcile what we see in development with such traditional views (Herre et al., 1999; Laublichler and Maienschein, 2007; Leigh and Rowell, 1995; Newman, 2005).

This does not make the traditional views wrong, but the concentration on evolution in a way sidesteps what are arguably at least comparably important aspects of life. Recent research is making it possible to look in detail at what genes actually do, on the shorter and perhaps less illusory, uncompressed time scale on which life is actually lived. There, the standard selectioncentered view of what life is all about is not very accurate or helpful. Life is actually characterized largely by imprecisionand is 
a lot friendlier than its reputation. On the here-and-now scale, we see something quite different from the usual view. One might alter Dobzhansky's quip to something like "Nothing in life makes sense, except in the light of partially sequestered modularity....or combinatorial coding...or..."

Survival of the Fittest has served as a memorable image that has led biology into a particular interpretation of the nature of life, but it has distracted it from the shorter term view of life on the developmental scale. A lesson of modern developmental biology is to be careful about our imagery. 'Success through cooperation' might be better, because what we have learned is that life is more about getting along than getting ahead.

\section{Acknowledgments and Note}

This is a conceptual overview, not a literature review. From an overwhelmingly large literature, we have preferentially cited recent references or ones that provide general ideas or bibliographic sources. We thank three reviewers and the editors of this special issue for their helpful comments, and Veronica Hinman for discussion about regulatory networks and their evolution. Our work on this subject has been made possible by financial support from the Evan Pugh Professorship endowment at Penn State, by the National Science Foundation through grants BCS-0343442, BCS-0523637, and BCS-0725227, for which we are grateful.

\section{References}

AMUNDSON, R. (2005). The changing role of the embryo in evolutionary thought: Roots of evo-devo Cambridge studies in philosophy and biology. Cambridge University Press, Cambridge, UK.

ANCEL, L.W. and FONTANA, W. (2000). Plasticity, evolvability, and modularity in rna. J Exp Zoo/288: 242-283.

BALHOFF, J.P. and WRAY, G.A. (2005). Evolutionary analysis of the well characterized endo16 promoter reveals substantial variation within functional sites. Proc Natl Acad Sci USA 102: 8591-8596.

BARABASI, A.L. and OLTVAI, Z.N. (2004). Network biology: Understanding the cell's functional organization. Nat Rev Genet 5: 101-113.

BATESON, W. (1894). Materials for the study of variation, treated with special regard to discontinuity in the origin of species; reprint 1992 with new introductory essays. Macmillan, reprinted Johns Hopkins press, Baltimore, London.

BIRNEY, E.STAMATOYANNOPOULOS, J.A.DUTTA, A.GUIGO, R.GINGERAS, T.R.MARGULIES, E.H.WENG, Z.SNYDER, M.DERMITZAKIS, E.T.THURMAN, R.E. et al. (2007). Identification and analysis of functional elements in $1 \%$ of the human genome by the encode pilot project. Nature 447: 799-816.

BOONE, C., BUSSEY, H. and ANDREWS, B.J. (2007). Exploring genetic interactions and networks with yeast. Nat Rev Genet 8: 437-449.

BROWN, C.D., JOHNSON, D.S. and SIDOW, A. (2007). Functional architecture and evolution of transcriptional elements that drive gene coexpression. Science 317: $1557-1560$.

BUSS, L.W. (1987). The evolution of individuality. Princeton University Press, Princeton, NJ.

CARROLL, S., GRENIER, J. and WEATHERBEE, S. (2004). From DNA to diversity: Molecular genetics and the evolution of animal design. Blackwell, Malden, MA.

CARROLL, S.B. (2006). The making of the fittest: DNA and the ultimate forensic record of evolution. W.W. Norton \& Co., New York, N.Y.

CHUONG, C.M., WU, P., PLIKUS, M.V., JIANG, T.X. and WIDELITZ, R. (2005). Engineering stem cells into organs: Topobiological transformations demostrated by beak, feather, and other ectodermal organ morphogenesis. Curr Top Dev Biol72: 237-274.

CVEKL, A. and PIATIGORSKY, J. (1996). Lens development and crystallin gene expression: Many roles for pax-6. Bioessays 18: 621-630.

DARWIN, C. (1859). The origin of species. Murray, London.

DARWIN, C. (1900). The variation of animals and plants under domestication. D.
Appleton and company, New York.

DAVIDSON, E.H. (2001). Genomic regulatory systems: Development and evolution. Academic Press, San Diego, CA.

DAVIDSON, E.H. (2006). The regulatory genome: Gene regulatory networks in development and evolution. Elsevier, Burlington, MA.

DOBZHANSKY, T. (1973). Nothing in biology makes sense except in the light of evolution. Am Biol Teach 35: 125-129.

DOBZHANSKY, T. (1964). Biology, molecular and organismic. American Zoologist 4: $443-452$.

EYRE-WALKER, A. and KEIGHTLEY, P.D. (2007). The distribution of fitness effects of new mutations. Nat Rev Genet 8: 610-618.

EYRE-WALKER, A., WOOLFIT, M. and PHELPS, T. (2006). The distribution of fitness effects of new deleterious amino acid mutations in humans. Genetics 173: 891-900.

FISHER, R.A. (1918). The correlation between relatives on the supposition of mendelian inheritance. Trans $R$ Soc Edinb 52: 399-433.

FONTANA, W. (2002). Modelling 'evo-devo' with RNA. Bioessays 24: 1164-1177

FONTANA, W. and SCHUSTER, P. (1998). Continuity in evolution: On the nature of transitions. Science 280: 1451-1455.

GERHART, J. and KIRSCHNER, M. (1997). Cells, embryos, and evolution: Toward a cellular and developmental understanding of phenotypic variation and evolutionary adaptability. Blackwell Scientific., Malden, MA.

GIBBS, R.A.ROGERS, J.KATZE, M.G.BUMGARNER, R.WEINSTOCK G.M.MARDIS, E.R.REMINGTON, K.A.STRAUSBERG, R.L.VENTER, J.C.WILSON, R.K. et al. (2007). Evolutionary and biomedical insights from the rhesus macaque genome. Science 316: 222-234.

GILBERT, S. (2003). Developmental biology. Sinauer, Sunderland, MA.

GILBERT, S., OPITZ, J. and RAFF, R. (1996). Resynthesizing evolutionary and developmental biology. Dev Bio/173: 357-372.

GILBERT, S.F. (2001). Ecological developmental biology: Developmental biology meets the real world. Dev Bio/233: 1-12.

GILBERT, S.F. (2005). Mechanisms for the environmental regulation of gene expression: Ecological aspects of animal development. J Biosci30: 65-74.

GILBERT, S.F. and BOLKER, J.A. (2003). Ecological developmental biology: Preface to the symposium. Evol Dev 5: 3-8.

HALL, B.K. (1999). Evolutionary developmental biology. Kluwer, Norwell, MA.

HERRE, E.A., KNOWLTON, N., MUELLER, U.G. and REHNER, S.A. (1999). The evolution of mutualisms: Exploring the paths between conflict and cooperation. Trends Ecol Evol 14: 49-53.

HINMAN, V.F. and DAVIDSON, E.H. (2007). Evolutionary plasticity of developmental gene regulatory network architectures. Proc Nat/ Acad Sci USA 104: 19401949.

JABLONKA, E. and LAMB, M. (2006). Evolution in four dimensions: Genetic, epigenetic, behavioral, and symbolilc: Variation in the history of life. MIT Press, Cambridge, MA.

JERNVALL, J. and THESLEFF, I. (2000). Reiterative signaling and patterning during mammalian tooth morphogenesis. Mech Dev 92: 19-29.

KAPRANOV, P., CHENG, J., DIKE, S., NIX, D.A., DUTTAGUPTA, R., WILLINGHAM, A.T., STADLER, P.F., HERTEL, J., HACKERMULLER, J., HOFACKER, I.L. et al. (2007a). Rna maps reveal new rna classes and a possible function for pervasive transcription. Science 316: 1484-1488.

KAPRANOV, P., WILLINGHAM, A.T. and GINGERAS, T.R. (2007b). Genome-wide transcription and the implications for genomic organization. Nat Rev Genet 8 : 413-423.

KASHTAN, N., NOOR, E. and ALON, U. (2007). Varying environments can speed up evolution. Proc Natl Acad Sci USA 104: 13711-13716.

KIRSCHNER, M. and GERHART, J. (2005). The plausibility of life: Resolving darwin's dilemma. Yale University, New Haven, CT.

KONDRASHOV, A.S., SUNYAEV, S. and KONDRASHOV, F.A. (2002). Dobzhanskymuller incompatibilities in protein evolution. ProcNat/Acad Sci USA 99: 1487814883

KULATHINAL, R.J., BETTENCOURT, B.R. and HARTL, D.L. (2004). Compensated deleterious mutations in insect genomes. Science 306: 1553-1554. 
LAUBLICHLER, M. and MAIENSCHEIN, J. (2007). From embryology to evo-devo: A history of developmental evolution. MIT Press, Cambridge, MA.

LEIGH, E.G. and ROWELL, T. (1995). The evolution of mutualism and other forms of harmony at various levels of biological organization. Ecologie 26: 131-158.

LUDWIG, M.Z., PATEL, N.H. and KREITMAN, M. (1998). Functional analysis of eve stripe 2 enhancer evolution in drosophila: Rules governing conservation and change. Development 125: 949-58.

LYNCH, M. (2007a). The frailty of adaptive hypotheses for the origins of organismal complexity. Proc Natl Acad Sci USA 104 Suppl 1: 8597-604.

LYNCH, M. (2007b). The origin of genome architecture. Sinauer Associates, Sunderland, MA.

MAINI, P.K., BAKER, R.E. and CHUONG, C.M. (2006). Developmental biology. The turing model comes of molecular age. Science 314: 1397-8.

MATYS, V., FRICKE, E., GEFFERS, R., GOSSLING, E., HAUBROCK, M., HEHL, R., HORNISCHER, K., KARAS, D., KEL, A.E., KEL-MARGOULIS, O.V. et al. (2003). Transfac: Transcriptional regulation, from patterns to profiles. Nucleic Acids Res 31: 374-378.

MATYS, V., KEL-MARGOULIS, O.V., FRICKE, E., LIEBICH, I., LAND, S., BARREDIRRIE, A., REUTER, I., CHEKMENEV, D., KRULL, M., HORNISCHER, K. et al. (2006). Transfac and its module transcompel: Transcriptional gene regulation in eukaryotes. Nucleic Acids Res 34: D108-10.

MAYR, E. (1982). The growth of biological thought. Harvard University Press, Cambridge, MA.

MAYR, E. and PROVINE, W. (1980). The evolutionary synthesis: Perspectives on the unification of biology. Harvard University Press, Cambridge, MA.

MCGREGOR, A.P., ORGOGOZO, V., DELON, I., ZANET, J., SRINIVASAN, D.G., PAYRE, F. and STERN, D.L. (2007). Morphological evolution through multiple cis-regulatory mutations at a single gene. Nature 448: 587-590.

MEINHARDT, H. (1996). Models of biological pattern formation: Common mechanism in plant and animal development. Int J Dev Bio/40: 123-134.

MEINHARDT, H. (2001). Organizer and axes formation as a self-organizing process. Int J Dev Bio/45: 177-188.

MEINHARDT, H. (2003). The algorithmic beauty of sea shells. Springer Verlag, Heidelberg.

MURRAY, J. (2002). Mathematical biology. Springer Verlag, Berlin.

NEI, M. (2005). Selectionism and neutralism in molecular evolution. Mol Biol Evol 22: $2318-2342$

NEWMAN, S.A. (2005). The pre-mendelian, pre-darwinian world: Shifting relations between genetic and epigenetic mechanisms in early multicellular evolution. $J$ Biosci30: 75-85.

NIJHOUT, H.F. (1991). The development and evolution of butterfly wing patterns. Smithsonian Institution Press, Washington.

NONCHEV, S., MACONOCHIE, M., VESQUE, C., APARICIO, S., ARIZAMCNAUGHTON, L., MANZANARES, M., MARUTHAINAR, K., KUROIWA, A., BRENNER, S., CHARNAY, P. et al. (1996). The conserved role of krox-20 in directing hox gene expression during vertebrate hindbrain segmentation. Proc Natl Acad Sci USA 93: 9339-9345.

NOWAK, M.A. (2006). Five rules for the evolution of cooperation. Science 314: 1560-3.

OHNO, S. (1970). Evolution by gene duplication. Springer-Verlag, Berlin.

OHTA, T. (1992). The nearly neutral theory of molecular evolution. Annual Review of Ecology and Systematics 23: 263-286.

OHTA, T. (2000). Mechanisms of molecular evolution. Philos Trans $R$ Soc Lond $B$ Biol Sci355: 1623-1626.

OHTA, T. (2002). Near-neutrality in evolution of genes and gene regulation. Proc Natl Acad Sci USA 99: 16134-16137.

OLIVERI, P. and DAVIDSON, E.H. (2007). Development. Built to run, not fail. Science 315: 1510-1.

OYAMA, S. (2000). The ontogeny of information: Developmental systems and evolution. Duke University Press, Durham.

OYAMA, S., GRIFFITHS, P.E. and GRAY, R.D. (2001). Cycles of contingency: Developmental systems and evolution, MIT Press, Cambridge, MA.

PISPA, J., JUNG, H.-S., JERNVALL, J., KETTUNEN, P., MUSTONEN, T., TABATA, J.J., KERE, J. and THELSEFF, I. (1999). Cusp patterning defect in tabbymouse teeth and its partial rescue by fgf. Dev. Biol. 216: 521-534.

POLLARD, K.S., SALAMA, S.R., LAMBERT, N., LAMBOT, M.A., COPPENS, S., PEDERSEN, J.S., KATZMAN, S., KING, B., ONODERA, C., SIEPEL, A. et al. (2006). An rna gene expressed during cortical development evolved rapidly in humans. Nature 443: 167-72.

QUEITSCH, C., SANGSTER, T.A. and LINDQUIST, S. (2002). Hsp90 as a capacitor of phenotypic variation. Nature 417: 618-24.

RAFF, R.A. (1996). The shape of life: Genes, development, and the evolution of animal form. University of Chicago Press, Chicago.

SALAZAR-CIUDAD, I. (2006a). Developmental constraints vs. Variational properties: How pattern formation can help to understand evolution and development. $J$ Exp Zoolog B Mol Dev Evo/306: 107-125.

SALAZAR-CIUDAD, I. (2006b). On the origins of morphological disparity and its diverse developmental bases. Bioessays 28: 1112-1122.

SALAZAR-CIUDAD, I. and JERNVALL, J. (2004). How different types of pattern formation mechanisms affect the evolution of form and development. Evol Dev 6: 6-16.

SALAZAR-CIUDAD, I. and JERNVALL, J. (2005). Graduality and innovation in the evolution of complex phenotypes: Insights from development. J Exp Zoolog $B$ Mol Dev Evo/304: 619-631.

SALAZAR-CIUDAD, I., JERNVALL, J. and NEWMAN, S.A. (2003). Mechanisms of pattern formation in development and evolution. Development 130: 2027-2037.

SANGSTER, T.A., LINDQUIST, S. and QUEITSCH, C. (2004). Under cover: Causes, effects and implications of hsp90-mediated genetic capacitance. Bioessays 26: 348-362.

SCHLICHTING, C. and PIGLIUCCI, M. (1998). Phenotypic evolution: A reaction norm perspective. Sinauer Associates, Sunderland, MA.

SCHLOSSER, G. and WAGNER, G.P. (2007). A simple model of co-evolutionary dynamics caused by epistatic selection. J Theor Biol. 250: 48-65.

SICK, S., REINKER, S., TIMMER, J. and SCHLAKE, T. (2006). Wnt and dkk determine hair follicle spacing through a reaction-diffusion mechanism. Science 314: $1447-50$.

STERN, D. (2007). The developmental genetics of microevolution. In Tinkering: The microevolution of development. J Wiley, Chichester, UK.

TURING, A.M. (1952). The chemical basis of morphogenesis. 237: 37-72.

WADDINGTON, C.H. (1942). Canalization of development and he inheritance of acquired characters. Nature 150: 563-565.

WADDINGTON, C.H. (1962). Newpatterns in genetics and development. Columbia University Press, New York.

WAGNER, G.P. (2007). The developmental genetics of homology. Nat Rev Genet 8: $473-479$.

WAGNER, G.P. and PYLE, A.M. (2007). Tinkering with transcription factor proteins: The role of transcription factor adaptation in developmental evolution. Novartis Found Symp 284: 116-25.

WAGNER, G.P. and SCHLOSSER, G. (2003). Modularity in development and evolution, University of Chicago Press, Chicago.

WEBSTER, G. and GOODWIN, B. (1996). Form and transformation: Generative and relational principles in biology. Cambridge University Press, Cambridge, UK.

WEINREICH, D.M., DELANEY, N.F., DEPRISTO, M.A. and HARTL, D.L. (2006). Darwinian evolution can follow only very few mutational paths to fitter proteins. Science 312: 111-114.

WEISS, K.M. (2004). The smallest grain in the balance. EvolAnthropo/13: 122-126.

WEISS, K.M. (2005). The phenogenetic logic of life. Nat Rev Genet 6: 36-45.

WEISS, K.M. and BUCHANAN, A.V. (2004). Genetics and the logic of evolution. Wiley-Liss, New York.

WEISS, K.M. and BUCHANAN, A.V. (2009). The mermaid's tale. Four billion years of cooperation in the making of living things, Harvard University Press, Cambridge, MA.

WEST-EBERHARD, M.J. (2003). Developmental and evolutionary plasticity. Oxford University Press, New York.

WILKINS, A.S. (2002). The evolution of developmental pathways. Sinauer, Sunderland, MA.

WILLINGHAM, A.T., DIKE, S., CHENG, J., MANAK, J.R., BELL, I., CHEUNG, E., 
DRENKOW, J., DUMAIS, E., DUTTAGUPTA, R., GANESH, M. et al. (2006). Transcriptional landscape of the human and fly genomes: Nonlinear and multifunctional modular model of transcriptomes. Cold Spring Harb Symp Quant Bio/71: 101-110

WOLPERT, L. (1996). One hundred years of positional information. Trends Genet. 12: 359-364.

WOLPERT, L., BEDDINGTON, R., BROCKES, J., JESSELL, T., LAWRENCE, P. and MEYEROWITZ, E. (1998). Principles of development. Current Biology Ltd,
London.

WRAY, G.A. (2003). Transcriptional regulation and the evolution of development Int. J. Dev. Biol. 47: 675-684.

WRAY, G.A. and ABOUHEIF, E. (1998). When is homology not homology? Curr Opin Genet Dev 8: 675-680.

WRAY, G.A., HAHN, M.W., ABOUHEIF, E., BALHOFF, J.P., PIZER, M., ROCKMAN M.V. and ROMANO, L. (2003). The evolution of transcriptional regulation in eukaryotes. Mol Biol Evol20: 1377-1419.

\section{Further Related Reading, published previously in the Int. J. Dev. Biol.}

See our Special Issue Evolution \& Development, edited by Jaume Baguñà and Jordi García-Fernández at:

http://www.ijdb.ehu.es/web/contents.php?vol=47\&issue=7-8

See our Special Issue Fertilization, in honor of David L. Garbers and edited by Paul M. Wassarman and Victor D. Vacquier at: http://www.ijdb.ehu.es/web/contents.php?vol=52\&issue=5-6

From Chemical Embryology to Nucleosome Patterning - an interview with Roumen G. Tsanev

Stefan Nonchev and Irina Tsaneva

Int. J. Dev. Biol. (2009) 53: 383-391

Lef1 plays a role in patterning the mesoderm and ectoderm in Xenopus tropicalis Giulietta Roël, Yoony Y.J. Gent, Josi Peterson-Maduro, Fons J. Verbeek and Olivier Destrée Int. J. Dev. Biol. (2009) 53: 81-89

Non-genic transcription at the Drosophila bithorax complex - functional activity of the dark matter of the genome

Margaret C.W. Ho, Benjamin J. Schiller, Sara E. Goetz and Robert A. Drewell

Int. J. Dev. Biol. doi: 10.1387/ijdb.082647mh

Genomic control of patterning

Isabelle S. Peter and Eric H. Davidson

Int. J. Dev. Biol. doi: 10.1387/ijdb.072495ip

Dynamical patterning modules: a "pattern language" for development and evolution of multicellular form

Stuart A. Newman and Ramray Bhat

Int. J. Dev. Biol. doi: 10.1387/ijdb.072481sn

Ectopic Meis1 expression in the mouse limb bud alters P-D patterning in a Pbx1independent manner

Nadia Mercader, Licia Selleri, Luis Miguel Criado, Pilar Pallares, Carlos Parras, Michael L. Cleary and Miguel Torres

Int. J. Dev. Biol. doi: 10.1387/ijdb.072430nm

Principles of branch formation and branch patterning in Hydrozoa

Stefan Berking

Int. J. Dev. Biol. (2006) 50: 123-134

Integument pattern formation involves genetic and epigenetic controls: feather arrays simulated by digital hormone models.

Ting-Xin Jiang, Randall B Widelitz, Wei-Min Shen, Peter Will, Da-Yu Wu, Chih-Min Lin, Han-

Sung Jung and Cheng-Ming Chuong

Int. J. Dev. Biol. (2004) 48: 117-135

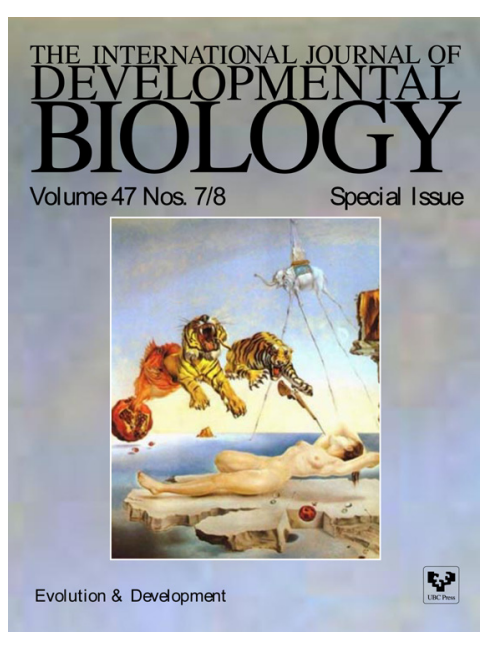

5 yr ISI Impact Factor $(2008)=3.271$

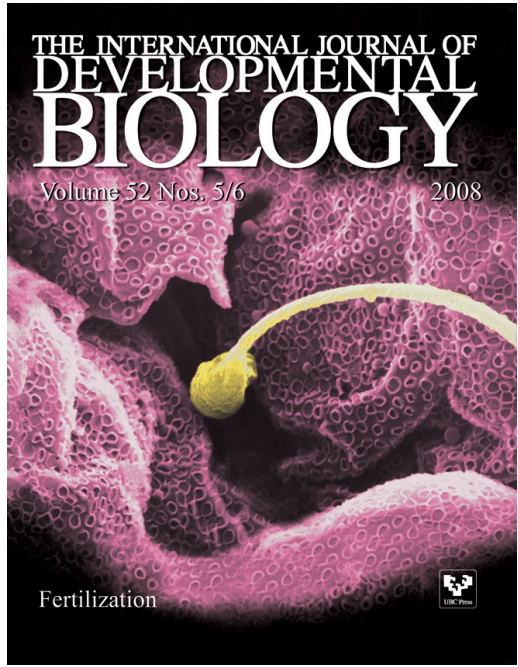




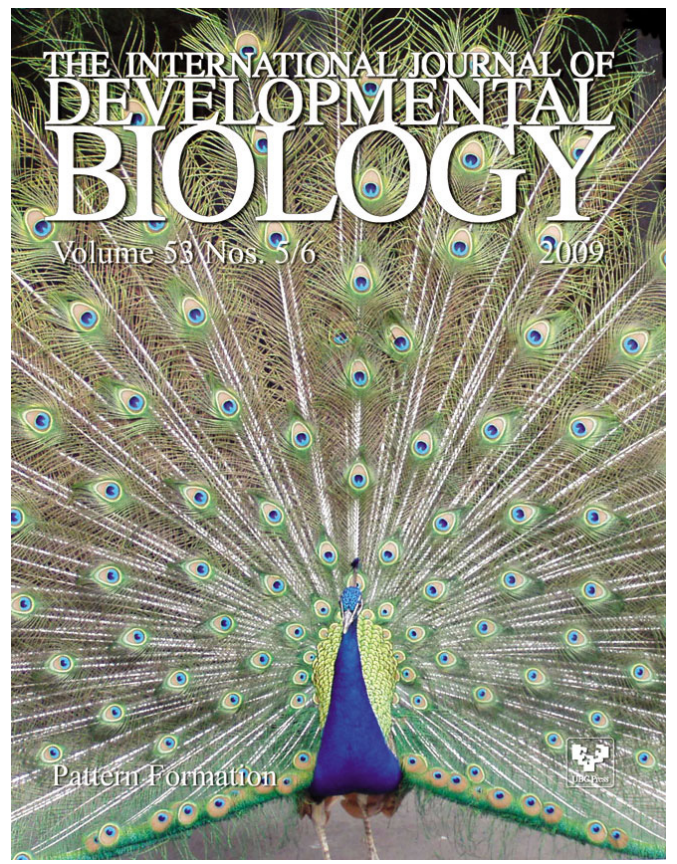

5 yr ISI Impact Factor $(2008)=3.271$

For all the latest on Pattern Formation research, see our latest Special Issue edited by C.-M. Chuong and M.K. Richardson.

http://www.ijdb.ehu.es/web/contents.php?vol=53\&issue=5-6 